\title{
ALGUMAS NOTAS EM TORNO DO DIÁLOGO DE PAUL RICOEUR COM SER E TEMPO
}

\section{FERNANDA HENRIQUES ${ }^{1}$}

RESUMO: Tal como o título indica, este texto é constituído por algumas notas reflexivas em torno da posição de Paul Ricoeur sobre Ser e Tempo. Não se trata de fazer uma análise sistemática da posição do autor no conjunto da sua obra, nem sequer, tão pouco, de fazer uma revisão de literatura sobre o tema da relação de Heidegger e Ricoeur. Trata-se, apenas, de acompanhar a apreciação de Ricoeur a Ser e Tempo, no âmbito das suas lições de Louvaina de 1971/72, apreciação que vai marcar o papel que Heidegger desempenhará na conceção hermenêutica de Ricoeur.

PALAVRAS-CHAVE: Epistemologia, ontologia, hermenêutica, método.

\begin{abstract}
As the title indicates, this text consists of some reflexive notes about Paul Ricoeur's position on Being and Time. It is not a matter of systematically analyzing the author's position in the whole of his work, nor even of doing a literature review on the subject of Heidegger's and Ricoeur's relationship. It is only a matter of following Ricoeur's appraisal of Being and Time, in the context of his Lessons of Louvaina, 1971/72, which will mark the role that Heidegger will play in Ricoeur's hermeneutic conception.
\end{abstract}

KEYWORDS: Epistemology, ontology, hermeneutics, method.

A obra de Paul Ricoeur instaura-se a partir do diálogo e entretece-se através da discussão, sendo que, diálogo e discussão nunca se estabelecem apenas entre o autor e uma outra instância - outro autor ou autora ou uma situação teórica - mas sim constituindo, pelo menos, um triângulo, isto é, envolvendo Paul Ricoeur, o interlocutor direto e um terceiro elemento que funciona como uma espécie de referência ou contexto.

Esta vontade de diálogo e de discussão que caracterizam a prática filosófica de Paul Ricoeur inscreve-se, diretamente, na sua conceção da fragmentação constitutiva do campo hermenêutico e da necessidade do Conflito de Interpretações como processo de superação da finitude racional em contraste com o excesso de sentido do real. Aliás, numa certa medida, o conjunto da obra do autor funciona como um espelho desse conflito interpretativo.

\footnotetext{
${ }^{1}$ Professora Emérita de Filosofia da Universidade de Évora. e-mail: maria.mariafern@gmail.com
} 
Heidegger intervém na textualidade ricoeuriana quer como dialogante direto quer como figura contextual, sendo Ser e Tempo o recurso mais sistemático dessa intervenção. Embora não se proponha fazer uma análise sistemática do diálogo ricoeuriano com Heidegger, o presente texto propõe-se sistematizar algumas linhas essenciais da leitura que Ricoeur faz de Ser e Tempo, nomeadamente, a importância do debate que estabelece com Heidegger no contexto da constituição da sua hermenêutica.

\section{A apreciação global de Ser e Tempo no curso de Louvaina de 1971/72}

No ano letivo de 1971/72, no rescaldo das ocorrências do "maio de 68", em Nanterre e já de posse da teorização essencial da sua filosofia hermenêutica, Paul Ricoeur lecionou um curso sobre hermenêutica, cujas lições foram editadas pelos serviços editoriais da universidade. É na segunda parte do curso, intitulada A teoria da Interpretação - Questões de Fundamento, que aparece a apresentação e a apreciação de Ser e Tempo, sendo a sua emergência referida dentro de um quadro instaurador de rutura. Diz Paul Ricoeur: "Este capítulo é consagrado, no essencial, à inversão operada por Ser e Tempo ao nível do problema fundamental ou, dito de outra maneira, fundacional.” (RICOEUR, 1971/72, p. 99).E um pouco adiante: "É um livro extremamente bem organizado, não impenetrável, mas sim de uma grande transparência. Avança por um processo concêntrico, da periferia para o centro." (RICOEUR, 1971/72, p. 106). E, como um fiel leitor de textos, faz uma síntese, esquematizando que:

- Se começa por refletir sobre o ser-no-mundo.

- A seguir se desenvolve o polo mundo, para retirar todo o privilégio ao sujeito enquanto tal.

- Depois interroga-se o que significa "être-dans", ou seja, qual é o sentido da espacialidade da existência que não se reduz a uma simples espacialidade geométrica.

- Finalmente, trata a questão do $d a$, do Dasein, no quadro da qual surgirá a questão do compreender.

Da análise sistemática de Paul Ricoeur, vou realçar, por minha conta, as três ruturas fundamentais que Ser e Tempo terá operado, por me parecer que elas são determinantes da leitura ricoeuriana do papel desta obra no decurso da filosofia posterior e, muito especialmente, do desenvolvimento da Hermenêutica Moderna. 
1.

Em primeiro lugar, importa salientar a rutura que é instauradora de todas as outras, a saber, a deslocação da reflexão filosófica do plano epistemológico para o plano ontológico que, por sua vez determina: (1) a refundação do lugar da filosofia que não poderá ser apenas o puro transcendental tal como a crítica kantiana tinha determinado; (2) a deslocação do lugar da reflexão sobre as Ciências do Espírito que Schleiermacher e Dilthey tinham levado a cabo; (3) a configuração da hermenêutica como a expressão do modo ontológico da reflexão filosófica.

Diz o texto, neste quadro, que Ser e Tempo faz emergir uma questão nova: “em lugar de se perguntar 'como se conhece' (ou compreende), passa-se a perguntar 'qual é o modo de ser deste ente que só existe compreendendo'?, podendo concluir a sua análise acrescentando: "em resumo, a partir daqui a interrogação debruça-se sobre a constituição ontológica da compreensão" (RICOEUR, 1971/72, p.99).

A preocupação ricoeuriana central é sublinhar que o Dasein não significa nem ser humano nem sujeito de um objeto. Ele é tão só o lugar onde surge a questão do ser. Por esse motivo, é a estrutura ontológica deste ente que transporta consigo a questão do ser que se impõe mostrar ou explicitar. Por isso, também, pensar filosoficamente a questão das Ciências do Espírito obriga à deslocação de perspetiva acima enunciada: não se tratará mais de as fundamentar e sim de as fundar. Citando, Heidegger, Ricoeur dirá: "portanto, o que está em jogo ou é o fulcro da problemática é então 'a explicitação do ente em relação à sua constituição de ser"” (RICOEUR, 1971/72, p.100).

E mais à frente:

assim, não se acrescentará nada à metodologia das Ciências do Espírito [...]em história, por exemplo, o que é filosoficamente primeiro não é nem a teoria da formação dos conceitos em matéria histórica, nem a teoria do conhecimento histórico, nem sequer a teoria da história, mas sim a interpretação do ente propriamente histórico relativamente à sua historicidade (RICOEUR, 1971/72, p.101).

Para concluir, no final da análise: “A filosofia de Heidegger começa, pois, por uma luta contra a pretensão de colocar as questões de método antes da investigação da coisa mesma; pelo contrário, ele quererá subordinar o método ao objeto.” (RICOEUR, 1971/72, p 101). 
2.

A segunda rutura instaurada por Ser e Tempo é aquilo que pode ser designado por mundanização ligado à prioridade dada ao ser-no-mundo.

Ainda ao invés de Schleiermacher e de Dilthey, para quem a comunicação entre subjetividades era o fulcro questionante, colocando a questão da compreensão diretamente ligada com a da alteridade, "em Ser e Tempo, a questão da compreensão está completamente desligada da comunicação com. [...] Os fundamentos do problema ontológico devem ser procurados na relação do ser com o mundo e não na relação com o outro alguém" (RICOEUR, 1971/72, p. 103) [grifo nosso]. Ou seja:

- O mundo toma o lugar do outro alguém.

- A reflexão tem de se centrar no ser-em e não no ser-com.

- A compreensão despsicologiza-se.

Para Paul Ricoeur, esta rutura é absolutamente fundamental, na medida em que ela se articula diretamente com a sua posição, defendida desde a sua obra dos anos 50, Le volontaire et l'involontaire, do enraizamento da subjetividade, posição essa que o levou sempre a tomar o Cogito na sua dimensão corporal, incarnado, e, portanto, fora dos quadros de uma pureza transcendental ${ }^{2}$. Por outro lado, o conceito de mundo está muito presente na obra de Paul Ricoeur. Por exemplo, em Interpretation Theory, Ricoeur dirá que mundo é "o conjunto das referências desveladas por cada um dos tipos de texto, descritivo ou poético, que li, compreendi e amei"(RICOEUR, 1976, p. 37) para, na sequência, evocando a análise heideggeriana de Verstehen em Ser e Tempo, completar aquela caracterização, dizendo: “aquilo que primeiro compreendemos num discurso não é a outra pessoa, mas um 'projeto', isto é, o esboço de uma nova maneira de ser no mundo". "(RICOEUR, 1976, p. 37).

3.

Mais do que uma rutura, há uma posição aberta por Ser e Tempo que leva Paul Ricoeur a dizer que "a filosofia de Heidegger é uma filosofia que vai em direção à linguagem e não uma filosofia que parte da linguagem"(RICOEUR, 1971/72, p.106).

No meu entender, esta leitura de Ricoeur decorre diretamente das duas posições anteriores, isto é, a radicação ontológica da reflexão filosófica e a sua "espacialização" ou

\footnotetext{
${ }^{2}$ Por essa razão, embora Le volontaire et l'involontaire se integre no campo fenomenológico, ela não se propõe fazer uma descrição pura dos dados da consciência e sim o que se designa como uma descrição compreensiva.
} 
mundanização. Contudo, à primeira vista, parece haver aqui um problema, tendo em atenção os existenciários, no quadro da Analítica do Dasein. Por outras palavras, como é que esta afirmação se compatibiliza com a co-originaridade do sentir-se, do compreender e da linguagem?

Penso que a afirmação de que a filosofia de Heidegger não parte da linguagem, mas chega a ela se compreende sem contradição com a co-originaridade dos existenciários se se entender e enfatizar a dimensão de passividade da Analítica do Dasein, na medida em que ela parte do encontrar-se em a existência como pura abertura, ou seja, numa posição de radical receptividade.

O acompanhamento interpretativo de Paul Ricoeur - que termina a sua análise dizendo que, em Heidegger, o discurso reenvia às coisas ditas e não ao sujeito falante - parece-me ir, exatamente, nessa direção, por duas razões.

- Antes de mais, pelo acentuar do carater de "mostração" do enunciado: aquilo que o enunciado traz de novo ao processo de análise é apenas isso - exibir articuladamente o ente a que se refere, ou, em palavras de Ricoeur, a dimensão de mostração do enunciado "acentua o próprio ente que é designado" " (RICOEUR, 1971/72, p. 114). Por sua vez a predicação - que determina o ente pela acentuação do predicado - não produz nenhum aumento de sentido, mas sim uma restrição. E Paul Ricoeur cita, de novo, Heidegger:“o que é enunciado pela enunciação de acordo com a segunda significação, i. é., o determinado enquanto tal, tem um sentido mais restrito do que aquilo que é enunciado através da primeira significação" (RICOEUR, 1971/72, p. 114).

- Por outro lado, pela maneira como o discurso (Rede) é abordado em Ser e Tempo não só porque na sua natureza de existenciário o discurso significa apenas a articulação da compreensão, mas também pela precedência da escuta em relação quer ao falar quer ao dizer; ou seja, em Ser e Tempo, a relação com a linguagem não é primariamente produção, mas sim recepção.

É esta leitura de Ser e Tempo, bem como o seu enquadramento na constituição da Hermenêutica Moderna, que terá uma importância central no modo como Paul Ricoeur vai constituir a sua própria posição hermenêutica. 


\section{A leitura ricoeuriana de Ser e Tempo no quadro da Hermenêutica Moderna e a especificidade da sua Hermenêutica}

Como é bem conhecido, a prática filosófica ricoeuriana radica na fenomenologia, sendo que o seu projeto filosófico - a Filosofia da Vontade - está formulado em termos fenomenológicos, configurando uma eidética, uma empírica e uma poética da vontade (Ricoeur, 1950). Por outro lado, a sua preocupação foi sempre articular a hermenêutica com a fenomenologia, desde que, em Symbolique du Mal (RICOEUR, 1960), desenvolve pela primeira vez, de modo sistemático, uma hermenêutica dos textos onde a humanidade deixou plasmada a sua vivência e a sua perplexidade sobre a existência do mal, desde hinos religiosos até aos mitos da origem e à tragédia grega. A continuação da sua compreensão da questão do mal prossegue através da sua análise da perspetiva freudiana, sendo que o livro I da sua obra sobre Freud (RICOEUR, 1965) representa um dos momentos fundamentais da sua teorização hermenêutica que se desenvolverá sempre no quadro de uma relação com a fenomenologia. Ricoeur nunca deixará de defender a necessidade de uma relação dialética entre hermenêutica e fenomenologia, defendendo que, por um lado, aquilo que é mais específico da perspetiva hermenêutica radica na fenomenologia, como é o caso do primado da compreensão de si e da emergência da questão do sentido, e, por outro, que a hermenêutica cumpre a destinação intrínseca da fenomenologia, sobretudo ao pôr a descoberto a constitutiva opacidade da consciência a si mesma, evidenciando o primado da pré-compreensão.

Outra linha de compreensão da especificidade da hermenêutica ricoeuriana diz respeito ao modo como ele interpreta quer o nascimento da Hermenêutica Moderna quer o seu contexto de emergência, sendo de realçar dois aspetos:

- A ideia de que o nascimento da Hermenêutica Moderna, no quadro da configuração da questão da compreensão como questão filosófica, está ligado à busca de um estatuto para as Ciências do Espírito.

- A importância dos contextos filosófico-culturais na possibilidade de configuração da problemática da compreensão como questão específica.

Dos elementos culturais contextuais da situação da Hermenêutica Moderna, vale a pena destacar, sobretudo, a importância do kantismo que, através do espírito da crítica, põe de manifesto que a capacidade de conhecer deve ser anterior ao confronto com a questão do ser, 
legitimando que uma teoria dos signos possa preceder uma teoria das coisas ou que a constituição de uma teoria da compreensão possa valer por si, independentemente dos conteúdos a que se aplique. É neste contexto que releva a importância de Schleiermacher e a sua vontade de construir uma Kunstlehre, isto é, uma teoria geral da compreensão enquanto fenómeno fundante das interpretações. Por este motivo, embora Ricoeur classifique a hermenêutica de Schleiermacher como romântica, também a considera crítica, uma vez que se propõe formular regras universalmente válidas da compreensão (RICOEUR, 1986).

Contudo, por outro lado, Kant apenas tratou do conhecimento das ciências físicas, criando um fosso entre a razão teórica e a razão prática que é uma razão moral. O trabalho de Dilthey vai ser prosseguir quer Schleiermacher quer Kant, procurando fazer uma crítica da razão histórica.

Do ponto de vista de Paul Ricoeur, Dilthey vai realizar o projeto iniciado por Schleiermacher levando a Hermenêutica a um ponto de crise, em função do horizonte historicista e psicologista da sua resposta que se articulam com as suas duas dimensões epocais: (1) o desenvolvimento do conhecimento histórico na Alemanha do sec XIX e (2) a grande importância do pensamento positivista. Em resposta, a investigação diltheyana configurará as duas interrogações do seu projeto hermenêutico: (1) Como é que a História é possível como ciência e (2) quais são as condições metodológicas que tornam possíveis as Ciências do Espírito.

Assim, quer Schleiermacher quer Dilthey situam a sua investigação numa linha epistemológica, sendo, como já se viu, Heidegger que vem introduzir uma rutura neste percurso, deslocando a questão em análise, em duas perspetivas, como também foi visto antes: (1) afirmando a prioridade do campo ontológico e, como consequência (2) transformando a busca de um fundamento, sempre epistemológica, na busca de uma fundação ontológica.

Considerando, embora, que Heidegger é incontornável na constituição da Hermenêutica, Ricoeur vai demarcar-se dele, por recusar ver como alternativas excludentes as dimensões epistemológica e ontológica. Tal recusa, por um lado, decorre diretamente da posição ricoeuriana sobre a natureza intrinsecamente dialógica da prática filosófica porque, para além de outras razões, considera a filosofia tematicamente receptiva; mas, por outro lado, no caso particular em que se particulariza, o do fosso entre fundamento epistemológico e fundação ontológica, assenta na ideia de que “(...) uma filosofia que rompe o diálogo com as ciências apenas se dirige a si mesma"(RICOEUR, 1986, p. 94). Nesse sentido, para ele, uma 
resposta pós-heideggeriana à definição da Hermenêutica tem de ser capaz de dialetizar a alternativa entre epistemologia e ontologia e encontrar mediações que a viabilizem e que corporizará naquilo que designa como a via longa de uma filosofia hermenêutica se relacionar com a ontologia.

É em Existence et Herméneutique, abertura da obra Le conflit des interprétations(1969), que Paul Ricoeur legitima a sua via longa em contraposição à perspetiva heideggeriana que designa como via curta, por ser uma ontologia da compreensão. Neste texto, Heidegger é, simultaneamente um interlocutor direto e o horizonte de referência de toda a reflexão.

Tal como Heidegger, Ricoeur também quer situar-se no plano ontológico, mas ele será o ponto de chegada e não o ponto de partida. Diz o autor: "a via longa que eu proponho também tem por ambição levar a reflexão ao nível de uma ontologia, mas fá-lo-á por graus, seguindo as exigências sucessivas da semântica e da reflexão.” (RICOEUR, 1969, p.10).

De um certo ponto de vista, a via longa situa-se nos antípodas da posição heideggeriana, ainda que seja ele quem se mantém como referencial dela, porque atingir o plano ontológico, ao invés de partir dele, por um lado, decorre de divergências filosóficas essenciais e, por outro, determina aquisições igualmente divergentes.

Antes de mais, a via longa de Ricoeur é o corolário direto daquilo que se referiu acima como a dependência temática da filosofia em relação ao seu entorno, nomeadamente, a sua articulação com as ciências, mas, ao mesmo tempo, ela representa uma preocupação epistemológica essencial que em nenhum momento quer abandonar a importância do método. Deste modo, Ricoeur, compreendendo claramente a proposta heideggeriana de "reeducar os nossos olhos e reorientar o nosso olhar" (RICOEUR, 1969, p.14), prefere fazer um percurso que permita acompanhar os caminhos metodológicas de todas as ciências da interpretação e, por isso, partir da linguagem e

substituir a via curta da Analítica do Dasein pela via longa iniciada pelas análises da linguagem; deste modo, manteremos constantemente o contacto com as disciplinas que procuram praticar a interpretação de uma forma metódica e resistiremos à tentação de separar a verdade, própria da compreensão, do método desenvolvido pelas disciplinas derivadas da exegese (RICOEUR, 1969, p. 14-15) ${ }^{3}$.

\footnotetext{
${ }^{3}$ Neste excerto, Ricoeur afasta-se, igualmente, da linha gadameriana da rutura entre verdade e método, no fundo, pela mesma razão.
} 
O plano da linguagem é, portanto, um lugar de convergência de todos os processos hermenêuticos e das suas articulações; por isso, deve ser o lugar onde começa uma reflexão filosófica que não quer enclausurar-se e falar para si mesma.

Por outro lado, a via longa vai afirmar outra dimensão contrária à perspetiva heideggeriana: o valor filosófico da subjetividade. Tal como para Heidegger, também para Ricoeur o ser humano não é um sujeito de um objeto, mas a compreensão/saber de si é um momento fundamental no processo de fundar a hermenêutica na fenomenologia: "A etapa intermediária em direção à existência é a reflexão, ou seja, o laço entre a compreensão dos signos e a compreensão de si. É neste si mesmo que nós temos a chance de reconhecer um existente." (RICOEUR, 1969, p. 20).

Este valor em si do momento subjetivo dentro do processo hermenêutico prende-se com a vontade reflexiva da filosofia ricoeuriana que sempre reiterará a sua pertença à tradição das filosofias da reflexão. Sendo desde o início crítico de um Cogito triunfante origem do sentido e transparente a si mesmo, Ricoeur pugnará sistematicamente pelo valor irrecusável da subjetividade e do seu saber de si, de que Soi-Même comme un autre é a explicitação clara.

A última etapa da via longa é a existencial, ou seja, a que se dimensiona no plano ontológico e, ao explicitar o seu sentido, Ricoeur pergunta:

\footnotetext{
Poder-se-á articular estas diferentes funções existenciais numa figura unitária, como Heidegger tentava na segunda parte de Sein und Zeit? Essa é a questão que o presente estudo deixa não resolvida. Mas se ela permanece não resolvida, ela não é desesperada. (RICOEUR, 1969, p. 27)
}

Não é desesperada, mas aceita que a hermenêutica seja uma tarefa interminável, à qual apenas uma decisão pode pôr fim. Como dizia no início da sua obra sobre Freud que "Nós hoje estamos à procura de uma grande filosofia da linguagem que dê conta das múltiplas funções do significar humano e das suas relações mútuas", salientando que "a unidade do falar humano constitui-se hoje como um problema”. (RICOEUR, 1965:13-14), também, ao atingir a etapa existencial da sua via longa, se terá de confrontar com o Conflito de Interpretações como a última fronteira da racionalidade, sendo a dialética das interpretações rivais o único modo humano de dirimir a incapacidade de reduzir as diferentes interpretações a uma unidade.

A meu ver, a este nível, aquilo que separa Heidegger de Ricoeur é o facto de que, para Heidegger, havia que procurar um outro pensar e, para Ricoeur, há que continuar a investir no poder da linguagem e do diálogo hermenêutico para prosseguir o caminho de compreensão de si e do mundo. 


\section{REFERÊNCIAS BIBLIOGRÁFICAS}

RICOEUR, P. Le Volontaire et l'involontaire. Paris Aubier-Montaigne, 1950.

RICOEUR, P. Interpretation Theory: discourse and the surplus of meaning. Texas The Texas Christian University Press, 1976.

RICOEUR, P. Herméneutique, Cours professé à Louvain,1971/1972. Louvain Éditions du SIC (policopiado).

RICOEUR, P. Finitude et Culpabilité. II. La symbolique du mal. Paris Aubier-Montaigne, 1960.

RICOEUR, P. De l'interprétation. Essai sur Freud. Paris Éditions du Seuil, 1965.

RICOEUR, P. Le conflit des interprétations. Essais d'herméneutique. Paris Éditions du Seuil, 1969.

RICOEUR, P. Du texte à l'action. Essais d'herméneutique, II. Paris Éditions du Seuil, 1986.

RICOEUR, P. Soi-même comme un autre. Paris Éditions du Seuil, 1990. 